\title{
Parsplana vitrectomy alone versus parsplana vitrectomy combined with phacoemulsification for the treatment of rhegmatogenous retinal detachment: a randomized study
}

Paolo Mora ${ }^{1 *}$ (i), Stefania Favilla ${ }^{2}$, Giacomo Calzetti ${ }^{1,3}$, Giulia Berselli ${ }^{1}$, Lucia Benatti ${ }^{1}$, Arturo Carta', Stefano Gandolfi ${ }^{1}$ and Salvatore A. Tedesco ${ }^{1}$

\begin{abstract}
Background: To compare parsplana vitrectomy (PPV) with and without phacoemulsification to treat rhegmatogenous retinal detachment (RRD).

Methods: Subjects aged 48-65 years with RRD in a phakic eye due to superior retinal tears with an overall extension of retinal breaks $<90^{\circ}$ underwent to PPV alone (group A); or PPV plus phacoemulsification (phacovitrectomy, PCV, group B). Post-operative follow-up visits occurred at 1 week, 1 month $(\mathrm{m} 1), 3$ months (m3), and 6 months (m6) after surgery. The main outcome was the rate of retinal reattachment. Secondary outcomes included best-corrected visual acuity (BCVA), intraocular pressure (IOP), central macular thickness (CMT), and cataract progression (in the lens-sparing [PPV-alone] group).

Results: In this initial phase of the study a total of 59 patients (mean age: 55 years, 59 eyes) were enrolled: 29 eyes in group A and 30 eyes in group B. Both groups had similar gas tamponade. During the follow-up there were three cases of RRD recurrence in group A and one in group B. The relative risk of recurrence in group A was 3.22 times higher but the difference was not significant ( $p=0.3$ ). The two groups were also similar in terms of BCVA and IOP variation. At $\mathrm{m} 3, \mathrm{CMT}$ was significantly higher in group $\mathrm{B}(p=0.014)$. In group $\mathrm{A}$, cataract progression was significant at $\mathrm{m6}(p=0.003)$.
\end{abstract}

Conclusions: In a cohort of RRD patients selected according to their preoperative clinical characteristics, PPV was comparable to PCV in terms of the rate of retinal reattachment after 6 months.

Trial registration: ISRCTN15940019. Date registered: 15/01/2021 (retrospectively registered).

Keywords: Rhegmatogenous retinal detachment, Parsplana vitrectomy, Phacovitrectomy, Retinal detachment recurrence, Cataract

\footnotetext{
* Correspondence: paolo.mora@unipr.it

'Ophthalmology Unit, Department of Medicine and Surgery, University

Hospital of Parma, via Gramsci 14, 43126 Parma, Italy

Full list of author information is available at the end of the article
}

\section{$\triangle B M C$}

C C The Author(s). 2021 Open Access This article is licensed under a Creative Commons Attribution 4.0 International License, which permits use, sharing, adaptation, distribution and reproduction in any medium or format, as long as you give appropriate credit to the original author(s) and the source, provide a link to the Creative Commons licence, and indicate if changes were made. The images or other third party material in this article are included in the article's Creative Commons licence, unless indicated otherwise in a credit line to the material. If material is not included in the article's Creative Commons licence and your intended use is not permitted by statutory regulation or exceeds the permitted use, you will need to obtain permission directly from the copyright holder. To view a copy of this licence, visit http://creativecommons.org/licenses/by/4.0/ The Creative Commons Public Domain Dedication waiver (http://creativecommons.org/publicdomain/zero/1.0/) applies to the data made available in this article, unless otherwise stated in a credit line to the data. 


\section{Background}

Rhegmatogenous retinal detachment (RRD) is a sightthreatening disease started by the formation of a retinal break. When the separation of the neurosensory retina from the retinal pigment epithelium has occurred, surgical management is required. The incidence of RRD has been reported to be between 6.3 and 17.9 per 100,000 population [1]. RRD is largely more common in adults with myopia or pseudophakic eyes but it can affect younger patients, particularly those with risk factors such as ocular trauma or hereditary ocular abnormalities [2-4]. Although scleral buckling surgery still plays a role in the management of some types of RRD, in recent years there has been a trend toward parsplana vitrectomy (PPV) as the primary procedure, maybe also because young surgeons are particularly familiar with this latter technique [5]. For phakic RRD, PPV can be performed with or without removing the lens, and previous studies have reported advantages and drawbacks for both approaches [6-10]. Phacovitrectomy (PCV), i.e., phacoemulsification combined with PPV, is associated with: a) enhanced retinal visualization during posterior segment surgery; b) better access to the vitreous base allowing for a more extensive vitrectomy and endolaser treatment (thereby ensuring more extensive gas filling and better tamponade of retinal breaks; and c) reduced risk through avoiding the need for a second surgery, which can be technically challenging due of the lack of vitreous support. However, there are also disadvantages of PCV: a) there is a risk of postoperative refractive errors, especially in macula-off cases; b) iatrogenic anisometropia is frequent in myopic subjects; and c) it can lead to the removal of a largely healthy organ in cases of no/ mild cataract with residual accommodative function. These latter issues can be avoided by performing a lens-sparing procedure (i.e. PPV-only).

PPV and PCV have been compared for the treatment of RRD in several recent large, retrospective studies [10-14]. One prospective series included two groups that underwent vitreoretinal surgeries for various pathologies [15]. Concerning the postoperative complications described in both techniques, the most dangerous for the visual prognosis include, besides the risk of endophthalmitis, the poor control of the intraocular pression (with either secondary glaucoma or hypotony), hemorrhage in the anterior and/or posterior segment of the eye, edema or morphological changes in the macular region, and the development of proliferative vitreoretinopathy (PVR) [11].

In this report, we present the results of a prospective randomized trial comparing PPV and PCV to treat RRD, with regard to the rate of retinal reattachment maintained during a 6-month follow-up (main outcome). As secondary outcomes, changes in best-corrected visual acuity, intraocular pressure, central macular thickness, and the progression of the cataract (for the PPV alone group) were also evaluated. To date, this is the largest randomized study comparing $\mathrm{PPV}$ alone and $\mathrm{PCV}$ to treat specifically the RRD.

\section{Methods}

\section{Patients and study design}

This hospital-based, parallel randomized study compared PPV with and without phacoemulsification of the lens for the treatment of RRD. This study, which was approved by the local Ethics Committee (registration number 569/ 2018) and adhered to the tenets of the Declaration of Helsinki and CONSORT guidelines, was conducted in the Ophthalmology Unit of the University Hospital of Parma (Parma, Italy) between December 2018 and November 2019. The inclusion criteria were as follows: 1) aged 4865 years with RRD in phakic eyes; 2) the presence of up to three separate retinal tears within the superior $180^{\circ}$ of the retinal circumference with an overall extension of retinal breaks $<90^{\circ}$; 3) PVR not exceeding the grade B according to the updated classification of 1991 [16]; and 4) lens opacity not exceeding the first grade of each category of the Lens Opacities Classification System III (LOCS III) scale [17]. The exclusion criteria were previous surgery in the affected eye (excluding corneal refractive procedures), current use of topical hypotensive medications, documented diabetic or hypertensive retinopathy, age-related maculopathy, and optic nerve vascular pathologies. The trial used equal randomization (i.e., 1:1) and the subjects were sequentially assigned to one of the two treatment groups by date of enrollment.

Patients scheduled for vitreoretinal surgery to treat RRD provided general and ocular medical history data, including current refractive correction, and underwent a slit lamp examination with applanation tonometry, lens opacity grading, and fundoscopy under mydriasis. Written informed consent was obtained from patients fulfilling the study criteria. All affected eyes of enrolled patients underwent preoperative optical coherence tomography (OCT; Cirrus HD-OCT 4000; Carl Zeiss Meditec, Dublin, CA, USA). In cases with macula-on $\mathrm{RRD}$, the axial length (AL) was evaluated using optical biometry (IOL-Master; Carl Zeiss Meditec). In cases with macula-off RRD, AL was measured using the combined vector-A/B-scan ultrasound biometry (B-scan Plus; Accutome, Malvern, PA, USA) technique [18]. The optimal intraocular lens (IOL) power was calculated using the Sanders-Retzlaff-Kraff/theoretical (SRK/T) formula, for all eyes except those with prior refractive surgery (for which we used the Barrett Universal II formula). All surgeries were performed by the same two surgeons (PM/ST) under general anesthesia or local anesthesia with sedation, according to the patient's general condition and predisposition. All patients were 
hospitalized on the day of surgery and discharged the next day after slit lamp examination of the anterior segment, fundus evaluation, and tonometry of the operated eye.

\section{Group A: Lens-sparing technique (PPV-only)}

PPV was performed using a binocular indirect ophthalmomicroscope (BIOM; Oculus, Wetzlar, Germany) for noncontact, wide-angle surgery. A 25-gauge trocar with a valved cannula (Alcon Laboratories Inc., Fort Worth, TX, USA) was inserted transconjunctivally in the inferotemporal, superotemporal, and superonasal quadrants, 4 $\mathrm{mm}$ posterior to the limbus. A 27-gauge twin bullet lights system was inserted at around the 1 and 11 o'clock meridians. This allowed the surgeon to independently indent the periphery externally with one hand and perform peripheral vitreous shaving with the other. All surgeries were performed using the Constellation Vitrectomy System (Alcon Laboratories Inc.). During the procedure, core vitrectomy was initially performed. When the posterior hyaloid was attached to the posterior pole, detachment was performed using the vitreous probe at an aspiration rate of $400 \mathrm{mmHg}$, without cutting. In all cases, visualization of the posterior hyaloid was facilitated by $0.05 \mathrm{~mL}$ of preservative-free triamcinolone acetonide (Taioftal ${ }^{\circ}$; Sooft Italia, SpA, Montegiorgio, Italy). Perfluorocarbon liquid (PFCL) was injected intravitreally up to around 2 disc diameters from the posterior edge of the less peripheral tear, to promote internal subretinal fluid drainage during fluid-air exchange. Cryopexy was used to freeze areas around the retinal breaks and those adjacent to the sclerotomies. Fluid-air exchange was then performed to remove all balanced saline solution and PFCL before gas tamponade (C3F8 at 18\%). At the end of surgery, all trocars were removed and sutures were placed according to the watertight nature of the holes. A subconjunctival injection of $0.2 \mathrm{~mL}$ of gentamicin and dexamethasone solution was administered before the lid speculum was removed.

\section{Group B: Phacovitrectomy}

Standard phacoemulsification was performed systematically before the PPV through a 2.2-mm clear corneal incision, with implantation of a hydrophobic, acrylic, foldable monofocal IOL (TECNIS ; Johnson \& Johnson, New Brunswick, NJ, USA). The subsequent vitrectomy procedure was the same as that mentioned above, except that argon endolaser treatment of the breaks was used instead of cryopexy.

\section{Postoperative regimen}

Both groups received from day 1 up to day 7 after surgery topical tropicamide $1 \%$ twice a day and a combination of tobramycin $0.3 \%$ and dexamethasone $0.1 \%, 6$ times per day. From week 2 to week 5 after surgery the topical combination of tobramycin $0.3 \%$ and dexamethasone $0.1 \%$ was tapered to 4 times per day.

The possible requirement for ocular hypotensive therapy and/or local adjunctive steroids was considered on a case-by-case basis according to the findings described below.

\section{Outcomes and follow up}

Primary study outcome: the anatomical success rate, defined as retinal reattachment 6 months after primary surgery without reoperation (postoperative argon laser treatment on areas considered to be at risk for new rhegmatogenous events was not considered as reoperation).

Secondary outcomes: final best-corrected visual acuity (BCVA), intraocular pressure (IOP), central macular thickness (CMT) and progression of the cataract (group A only). For the statistical analysis, this latter parameter was expressed as the sum of the scores for the affected eye on every LOCS III scale category at the follow-up visits.

Follow-up: all parameters defining the primary and secondary outcomes were assessed during postoperative follow-up visits scheduled at 1 week (w1), 1 month (m1), 3 months (m3), and 6 months (m6) after surgery ( \pm 7 days starting from $\mathrm{m} 1$ ). For BCVA, patients were asked to read the Early Treatment Diabetic Retinopathy chart, placed at $4 \mathrm{~m}$, until no more letters were identified correctly. The letters properly identified were then counted, and the corresponding $\log M A R$ was recorded. For IOP, applanation tonometry was performed before slit lamp examination. Two readings were performed. In the case of a $>2 \mathrm{mmHg}$ difference between the readings, a third one was obtained and the two closest values were averaged. For lens transparency, the state of the lens was assessed in full mydriasis with a slit lamp, by referring to the most similar grading photograph observed on a portable retro-illuminated chart showing the LOCS III classification system standard images.

Patients with retinal detachment recurrence dropped out of the study and were managed according to the most suitable procedure. Adverse events (related or unrelated to the study) occurring between study visits were recorded as having occurred at the time of the closest scheduled visit. An IOP value $\geq 25 \mathrm{mmHg}$ was taken to indicate the use of hypotensive drugs. OCT evidence of cysts or diffuse edema in the macular region necessitated subtenon injection of triamcinolone acetonide (Taioftal ${ }^{\circ}$; Sooft Italia), unless clinically contraindicated [19]. Laser treatment was performed postoperatively if new tears occurred and postoperative examination showed an insufficient effect of primary laser treatment or cryopexy.

\section{Sample size and statistical analysis}

A difference up to $10 \%$ in the achieving of the primary outcome was assumed as non-inferiority margin between 
the two procedures (i.e. $\delta=10 \%$ ). By accepting a type I error of $5 \%$ and a type II error of $20 \%$ (i.e. a study power of $80 \%$ ), a total sample size of 50 units (2 groups of 25 units) was required. The units correspond to the eyes assigned to each treatment group. The software used for the calculations is $\mathrm{G}$ * Power 3.1.9 [20].

Demographics and ocular baseline findings are given as percentages for categorical data and as mean \pm standard deviation (SD) for continuous variables. All analyses were performed using $\mathrm{R}$ software [21]. The primary outcome (retinal reattachment) was evaluated using Kaplan-Meier analysis and the log-rank test; the relative risk (RR) of detachment was determined for groups A and $\mathrm{B}$. The baseline group comparison for normally distributed variables was performed using Student's ttest, and proportions were compared using Fisher's exact test. All between- and within-group follow-up analyses were based on repeated-measures ANOVA (Analysis of variance) models. For post hoc contrast analysis, Fisher's least significant difference test ( $95 \%$ family-wise confidence level) was applied (Table 2). For all variables, $p$-values $<0.05$ were considered significant.

\section{Results}

Fifty-nine eyes of 59 patients (36 men and 23 women, mean age: 55 years) were enrolled for the study and randomly allocated to group A (29 eyes) or group B (30 eyes). Demographics and preoperative ocular findings are provided in Table 1. At baseline, the two groups showed no statistical difference.

Preoperatively, the presence of an incomplete posterior vitreous detachment (PVD) was observable in 8 eyes; of these 5 had PPV and 3 PCV. All surgeries were uneventful in terms of complications related to the lens (no capsule ruptures, crystalline lens contact, or IOL displacement), endophthalmitis, and procedures on the posterior segment. At the 1-day postoperative visit, the retina was attached in all operated eyes, although there were some cases of corneal edema and mild hyphema.

RRD recurred in three cases in group A (two after 1 month and one after 3 months) and in one case in group $B$ (at the $\mathrm{m} 3$ visit). The log-rank test revealed that the

Table 1 Demographics and preoperative ocular findings

\begin{tabular}{llll}
\hline PREOPERATIVE & Group A & Group B & $\boldsymbol{p}$-value \\
\hline SEX (\% females) & $34 \%$ & $43 \%$ & 0.415 \\
AGE (years) & $54 \pm 5$ & $56 \pm 7$ & 0.255 \\
SE (Dioptres) & $-4.27 \pm 4.90$ & $-3.18 \pm 3.83$ & 0.349 \\
IOP (mmHg) & $12.9 \pm 3.5$ & $14.1 \pm 2.8$ & 0.150 \\
MACULA ON-OFF (\% ON) & $41.38 \%$ & $33.33 \%$ & 0.406 \\
LENS OPACITY (LOCS III) & $0.38 \pm 0.77$ & $0.5 \pm 0.78$ & 0.553 \\
\hline
\end{tabular}

SE Spheric equivalent, IOP Intraocular pressure, LOCS III Lens Opacities Classification System III scale
RR of RRD recurrence was 3.22 times higher in group A than in group $\mathrm{B}$, but the difference was not significant $(p=0.3$; Fig. 1).

Regarding the secondary outcomes, both within- and between-group (Table 2) analyses were performed. In both groups, BCVA improved over time and was thus significantly better at $\mathrm{m} 6$ than at $\mathrm{w} 1(p=0.009$ and $p=$ 0.020 in groups $A$ and $B$, respectively). The final mean BCVA in group A $(0.19 \pm 0.18 \log$ MAR, Snellen equivalent of 20/32) was better than in group B $(0.28 \pm 0.23$ $\operatorname{logMAR}$, Snellen equivalent of $20 / 40$ ), but not significantly $(p=0.203)$. The two groups differed in terms of the increase in BCVA over time $(p=0.016)$. In group $\mathrm{A}$, the improvement was significant between $\mathrm{w} 1$ and $\mathrm{m} 1$ $(p=0.046)$; other changes throughout the subsequent follow up did not reach statistical significance. In group $B$, gradual increase in the BCVA was seen during the follow-up, but only the difference between w1 and $\mathrm{m} 6$ tested significant $(p<0.001)$.

Regarding the postoperative IOP values, a significant group difference was detected only at w1 higher in group A $(p<0.001)$. In group A, up to $\mathrm{m} 3$ the postoperative IOP was significantly higher than that preoperatively. Starting from $\mathrm{m} 3$, hypotensive treatment was prescribed in three eyes in group A, while it was administered in two eyes in group B starting from $\mathrm{m} 1$. In all cases, satisfactory IOP control was achieved.

The CMT, assessed based on the central subfield thickness as revealed by a $512 \times 128$ macular cube OCT scan (Cirrus HD-OCT 4000; Carl Zeiss Meditec), could be effectively analyzed only from $\mathrm{m} 1$ because of the poor quality of several of the earlier images (due to corneal edema and/or intraocular gas). The CMT was significantly greater in group B than group A at m3 $(p=0.014)$, with the two groups showing similar values thereafter. It should be noted that subtenon steroid injections were performed in five eyes of group B with cystoid macular edema at $\mathrm{m} 3$ (vs. 0 eyes in group A; $p=0.026$ with $\chi^{2}$-test). Due to the presence of cystoid macular edema at $\mathrm{m} 6$, steroid injections were performed in four eyes in group B (for the second time in three eyes), whereas no injections were required in group A ( $p=0.049$ with $\chi^{2}$-test).

Finally, compared to the preoperative examination, the mean total LOCS III score in group A was significantly different from baseline only at the end of the follow up (i.e., at m6; $1.31 \pm 1.74$ vs $0.35 \pm 0.75$ at baseline, $p=0.003)$.

\section{Discussion}

In our series, the rate of retinal reattachment at 6 months after PPV without cataract extraction (group A) was 89.7\%; in the PCV group (group B), the rate was 96.7\%. These data are consistent with those reported from prior studies dealing with the topic $[13,14,22-24]$. 


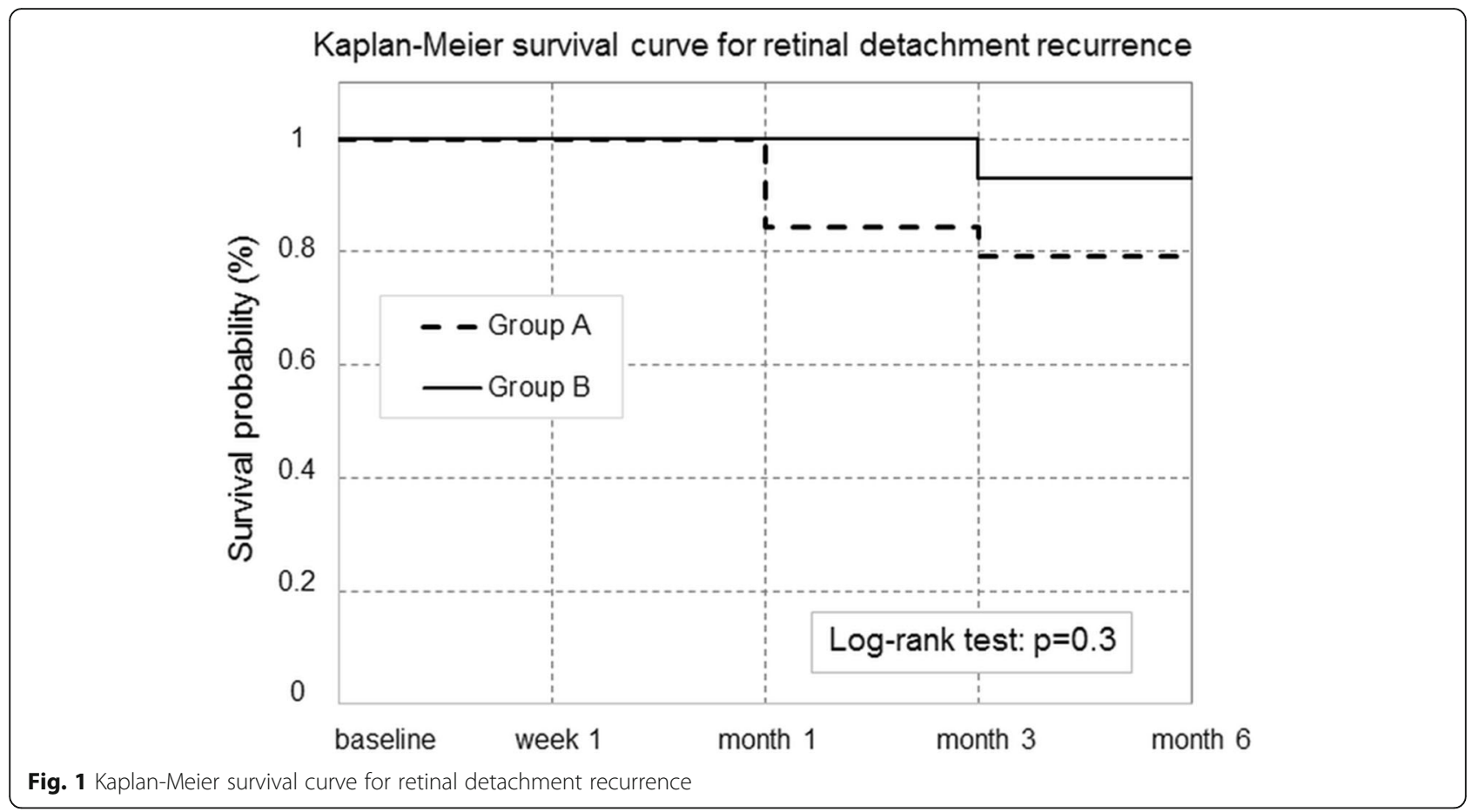

Group A had a RR of RRD recurrence 3.22 times higher than group $B$, but the difference was not significant. In total, we recorded four cases of recurrence, three of which were from previous macula-on RRD. All these first surgery failures were related to the occurrence of new retinal breaks in areas quite far from the original involvement. During the new surgeries, no clinically significant PVR was observed.

We think that in some RRD cases it is unsuitable to plan PPV alone in phakic eyes, particularly when: there is a large detachment with a traumatic etiology; extensive vitreous shaving is required (up to the base); there are tears suggestive of medium- to long-term viscous tamponade; or the lens is already showing opacity. Against this background, in our comparative study we included only cases of RRD in which lens-sparing surgery would be justified. The age selection minimized the likelihood of advanced cataract and absolute presbyopia; the other inclusion requirements were aimed to avoid some pre-existing characteristics which correlate with

Table 2 Evaluation of the secondary outcomes by between-group analyses

\begin{tabular}{|c|c|c|c|c|c|}
\hline \multirow{2}{*}{$\begin{array}{l}\text { Secondary } \\
\text { outcomes }\end{array}$} & \multirow[t]{2}{*}{ Group } & \multicolumn{4}{|l|}{ Time-points } \\
\hline & & $\begin{array}{l}\text { Week } 1 \\
\text { mean } \pm \text { s.d. }\end{array}$ & $\begin{array}{l}\text { Month } 1 \\
\text { mean } \pm \text { s.d. }\end{array}$ & $\begin{array}{l}\text { Month } 3 \\
\text { mean } \pm \text { s.d. }\end{array}$ & $\begin{array}{l}\text { Month } 6 \\
\text { mean } \pm \text { s.d. }\end{array}$ \\
\hline \multirow[t]{3}{*}{ BVCA (logMAR) } & A & $0.50 \pm 0.51$ & $0.26 \pm 0.16$ & $0.20 \pm 0.21$ & $0.19 \pm 0.18$ \\
\hline & B & $0.55 \pm 0.32$ & $0.37 \pm 0.26$ & $0.31 \pm 0.24$ & $0.28 \pm 0.23$ \\
\hline & $p$-value & n.s. & n.s. & n.s. & n.s. \\
\hline \multirow[t]{3}{*}{ IOP $(\mathrm{mmHg})$} & A & $17.7 \pm 7.0$ & $16.1 \pm 2.4$ & $15.9 \pm 3.0$ & $15.5 \pm 2.6$ \\
\hline & B & $13.7 \pm 3.3$ & $15.4 \pm 4.9$ & $14.9 \pm 3.3$ & $14.2 \pm 3.5$ \\
\hline & $p$-value & $<0.001$ & n.s. & n.s. & n.s. \\
\hline \multirow[t]{3}{*}{ CMT $(\mu \mathrm{m})$} & A & - & $279 \pm 26$ & $270 \pm 26$ & $270 \pm 25$ \\
\hline & B & - & $278 \pm 30$ & $316 \pm 118$ & $297 \pm 91$ \\
\hline & $p$-value & - & n.s. & 0.01 & n.s. \\
\hline \multirow[t]{2}{*}{ LOCS III } & A & $0.35 \pm 0.75$ & $0.54 \pm 0.90$ & $0.73 \pm 1.15$ & $1.31 \pm 1.74$ \\
\hline & $\begin{array}{l}p \text {-value } \\
\text { vs baseline }\end{array}$ & n.s & n.s & n.s & 0.003 \\
\hline
\end{tabular}

BCVA Best-corrected visual acuity, IOP Intraocular pressure, CMT Central macular thickness (by Optical Coherence Tomography), LOCS III Lens Opacities Classification System III scale 
lower single operation success rate [25]. Interestingly, Caiado et al. reported better success rates for PCV or PPV in already pseudophakic eyes [12]. The higher RR in group $\mathrm{A}$ is in accordance with these results, and the lack of a significant group difference in our study may be attributable to the preoperative selection of the cohort, comprising only cases with characteristics likely to account for the risk of a "non-near complete" vitreous removal.

Regarding our secondary outcomes, a significant improvement in BCVA was seen at the end of follow-up in both groups. The CMT was significantly higher in group $\mathrm{B}$ than group $\mathrm{A}$ at the $\mathrm{m} 3$ visit, and the presence of cystoid macular edema in group B cases necessitated significantly more local steroid injections than in group A. The return to baseline CMT values in both groups at the $\mathrm{m} 6$ evaluation indicated that the increase therein was transient, and that the subtenon injection of triamcinolone acetonide was safe and effective particularly when applied to pseudophakic eyes (group B). These results regarding CMT may accord with the postoperative inflammation described in other series of PCV [7, 15, $26]$. We did not investigated the possible presence of metamorphopsia or microperimetry alterations, as recently performed by Borowicz et al. in a cohort of vitrectomized RRD [27].

In the literature, the average delay between PPV (for any reason) and subsequent cataract extraction ranges from 16 to 24 months, which may justify preservation of a healthy crystalline lens at the time of PPV in selected cases $[6,28]$. However, cataract formation can occur even much earlier, regardless the caliber of the instruments and with a mechanism not completely understood [29]. The protective role of the vitreous gel against the direct interaction between the molecular oxygen from the retinal vasculature and the lens has been considered [30, 31]. In the light of these considerations, the management of a RRD while preserving the lens still involves scleral buckling; the preference with respect to vitrectomy often takes into account the absence of a preexisting PVD [5].

Preservation of the crystalline lens at the time of PPV in our RRD patients ensured similar outcomes to those obtained with PCV, in terms of the retinal reattachment rate and safety during postoperative management. However, the RR data for retinal detachment recurrence indicated that the possible superiority of combined surgery (PCV) should be discussed with the patient preoperatively. At the end of follow-up, the BCVA was similar between the two groups, although recovery over the follow-up was more rapid in group A. Sparing the natural lens was not associated with rapid worsening of the cataract. At the end of follow-up, lens opacity was more advanced than at the baseline, but the change was less than two LOCS III grades on average.
The limitations of this study included the relatively small sample size and short-duration follow-up preventing long-term outcome assessment. This particularly referred to eyes with preserved lens because of their potential for cataract progression and difficulties in performing the phacoemulsification in vitrectomized eyes. Moreover, retinal cauterization technique was not exactly the same in the two groups. Cryopexy was used in the lens-sparing group, while endolaser was performed in the case of PCV. This because, when there was no risk of lens contact, an ab interno extensive encircling of the rhegmatogenous areas was planned.

\section{Conclusion}

To treat phakic rhegmatogenous retinal detachment, mostly in non-presbyopic patients, parsplana vitrectomy (PPV) can be performed with or without removing the lens. In this randomized study comparing PPV with versus without phacoemulsification, the difference in the rate of retinal reattachment after 6 months was not statistically significant $(p=0.3)$. The relative risk for retinal detachment recurrence indicated that the possible superiority of combined surgery (phacovitrectomy) should be discussed with the patient preoperatively.

\section{Abbreviations}

AL: Axial length; ANOVA: Analysis of variance; BCVA: Best-corrected visual acuity; BIOM: Binocular indirect ophthalmomicroscope; CMT: Central macular thickness; IOL: Intraocular lens; IOP: Intraocular pressure; LOCS III: Lens Opacities Classification System III; M: Month; OCT: Optical coherence tomography; PCV: Phacovitrectomy; PFCL: Perfluorocarbon liquid; PPV: Parsplana vitrectomy; PVD: Posterior vitreous detachment;

PVR: Proliferative vitreoretinopathy; RR: Relative risk; RRD: Rhegmatogenous retinal detachment; SD: Standard deviation; SRK/T: Sanders-Retzlaff-Kraff/ theoretical formula; W: Week

\section{Acknowledgments}

The English in this document has been checked by at least two professional editors, both native speakers of English. For a certificate, please see: http:// www.textcheck.com/certificate/QXN1zu

\section{Authors' contributions}

PM and ST designed the work and performed surgeries; GB and LB for acquisition of data; SF for analysis of data; PM, ST, GC, AC, and SG for interpretation of data and drafting of the work. All authors read and approved the final manuscript.

Funding

No funding was received to assist with the preparation of this manuscript.

\section{Availability of data and materials}

The data that support the findings of this study are available from the corresponding author, PM, upon reasonable request.

\section{Declarations}

Ethics approval and consent to participate

All procedures performed in studies involving human participants were in accordance with ethical standards of the institutional and/or national research committee and with the 1964 Helsinki declaration and its later amendments or comparable ethical standards. The study was approved by the Bioethics Committee of the Medical University of Parma ("Area Vasta Emilia Nord" registration number 569/2018). Written informed consent was obtained from all individual participants included in the study. 


\section{Consent for publication}

Not Applicable.

\section{Competing interests}

The authors declare that they have no competing interests.

\section{Author details}

'Ophthalmology Unit, Department of Medicine and Surgery, University Hospital of Parma, via Gramsci 14, 43126 Parma, Italy. Independent Researcher, on behalf of the University of Parma, Parma, Italy. ${ }^{3}$ Institute of Molecular and Clinical Ophthalmology Basel, Basel, Switzerland.

Received: 7 December 2020 Accepted: 20 April 2021

Published online: 03 May 2021

\section{References}

1. Mitry D, Charteris DG, Fleck BW, et al. The epidemiology of rhegmatogenous retinal detachment: geographical variation and clinical associations. Br J Ophthalmol. 2010;94(6):678-84.

2. The Eye Disease Case-Control Study Group. Risk factors for idiopathic rhegmatogenous retinal detachment. Am J Epidemiol. 1993;137:749-57.

3. Weinberg DW, Lyon AT, Greenwald MJ, et al. Rhegmatogenous retinal detachments in children: risk factors and surgical outcomes. Ophthalmology. 2003;110(9):1708-13.

4. Garafalo AV, Calzetti G, Cideciyan AV, et al. Cone vision changes in the enhanced S-cone syndrome caused by NR2E3 gene mutations. Invest Ophthalmol Vis Sci. 2018;59(8):3209-19.

5. Noori J, Bilonick RA, Eller AW. Scleral buckle surgery for primary retinal detachment without posterior vitreous detachment. Retina. 2016:36(11): 2066-71. https://doi.org/10.1097//AE.0000000000001075.

6. Ahfat FG, Yuen $\mathrm{CH}$, Groenewald CP. Phacoemulsification and intraocular lens implantation following parsplana vitrectomy: a prospective study. Eye (Lond). 2003;17(1):16-20. https://doi.org/10.1038/sj.eye.6700232.

7. Smith M, Raman SV, Pappas G, et al. Phacovitrectomy for primary retinal detachment repair in presbyopes. Retina. 2007;27(4):462-7.

8. Cho KH, Park IW, Kwon SI. Changes in postoperative refractive outcomes following combined phacoemulsification and parsplana vitrectomy for rhegmatogenous retinal detachment. Am J Ophthalmol. 2014;158(2):251-256.e2.

9. Rahman R, Bong CX, Stephenson J. Accuracy of intraocular lens power estimation in eyes having phacovitrectomy for rhegmatogenous retinal detachment. Retina. 2014;34(7):1415-20. https://doi.org/10.1097/IAE. 0000000000000072 .

10. Loukovaara S, Haukka J. Repair of primary RRD - comparing parsplana vitrectomy procedure with combined phacovitrectomy with standard foldable intraocular lens implantation. Clin Ophthalmol. 2018;12:1449-57.

11. Lee JY, Kim KH, Shin KH, et al. Comparison of intraoperative complications of phacoemulsification between sequential and combined procedures of parsplana vitrectomy and cataract surgery. Retina. 2012;32(10):2026-33.

12. Caiado RR, Magalhães $\mathrm{O} \mathrm{Jr}$, Badaró E, et al. Effect of lens status in the surgical success of 23-gauge primary vitrectomy for the management of rhegmatogenous retinal detachment: the Pan American collaborative retina study (PACORES) group results. Retina. 2015;35(2):326-33.

13. Guber J, Bentivoglio M, Sturm V, et al. Combined parsplana vitrectomy with phacoemulsification for rhegmatogenous retinal detachment repair. Clin Ophthalmol. 2019;13:1587-91.

14. Tan A, Bertrand-Boiché M, Angioi-Duprez $K$, et al. Outcomes of combined phacoemulsification and parsplana vitrectomy for rhegmatogenous retinal detachment: a Comparative Study [published online ahead of print, 2020 Apr 3]. Retina. 2020. https://doi.org/10.1097//AE.0000000000002803.

15. Tayyab H, Khan AA, Javaid RMM. Clinical outcome of $23 \mathrm{~g}$ trans-Conjunctival parsplana vitrectomy - a prospective comparison of Phaco-Vitrectomy with only vitrectomy in phakic eyes. Pak J Med Sci. 2017;33(5):1123-7. https://doi. org/10.12669/pjms.335.13430.

16. Machemer R, Aaberg TM, Freeman HM, et al. An updated classification of retinal detachment with proliferative vitreoretinopathy. Am J Ophthalmol. 1991;112(2):159-65.

17. Chylack LT Jr, Wolfe JK, Singer DM, et al. The Lens Opacities Classification System III. The longitudinal study of cataract study group. Arch Ophthalmol. 1993;111(6):831-6. https://doi.org/10.1001/archopht.1993.01090060119035.
18. Abou-Shousha M, Helaly HA, Osman IM. The accuracy of axial length measurements in cases of macula-off retinal detachment. Can J Ophthalmol. 2016;51(2):108-12. https://doi.org/10.1016/j.jcjo.2015.12.011.

19. Lin JM, Chiu YT, Hung PT, Tsai YY. Early treatment of severe cystoid macular edema in central retinal vein occlusion with posterior sub-tenon triamcinolone acetonide. Retina. 2007;27(2):180-9. https://doi.org/10.1097/ 01.iae.0000237584.56552.1c.

20. Faul F, Erdfelder E, Buchner A, Lang AG. Statistical power analyses using G*Power 3.1: tests for correlation and regression analyses. Behav Res Methods. 2009:41(4):1149-60

21. R Core Team. R: A language and environment for statistical computing. Vienna: R Foundation for Statistical Computing; 2020. URL https://www.Rproject.org/

22. Ling R, Simcock P, McCoombes J, Shaw S. Presbyopic phacovitrectomy. Br J Ophthalmol. 2003;87(11):1333-5. https://doi.org/10.1136/bjo.87.11.1333.

23. Haugstad M, Moosmayer S, Bragadóttir R. Primary rhegmatogenous retinal detachment - surgical methods and anatomical outcome. Acta Ophthalmol. 2017;95(3):247-51. https://doi.org/10.1111/aos.13295.

24. Sallam AB, Donachie PHJ, Yorston D, et al. Royal College of ophthalmologists' National Database Study of Vitreoretinal surgery: report 7 , Intersurgeon variations in primary Rhegmatogenous retinal detachment failure. Retina. 2018:38(2):334-42.

25. Wykoff CC, Schwartz SG, Adelman RA, et al. Primary rhegmatogenous retinal detachment repair: evidence supports an individualised approach. $\mathrm{Br} J$ Ophthalmol. 2015;99(11):1451-3.

26. Jalil A, Steeples L, Subramani S, et al. Microincision cataract surgery combined with vitrectomy: a case series. Eye (Lond). 2014;28(4):386-9.

27. Borowicz D, Nowomiejska K, Nowakowska D, et al. Functional and morphological results of treatment of macula-on and macula-off rhegmatogenous retinal detachment with pars plana vitrectomy and sulfur hexafluoride gas tamponade. BMC Ophthalmol. 2019;19(1):118.

28. Feng $\mathrm{H}$, Adelman RA. Cataract formation following vitreoretinal procedures. Clin Ophthalmol. 2014;8:1957-65.

29. Almony A, Holekamp NM, Bai F, et al. Small-gauge vitrectomy does not protect against nuclear sclerotic cataract. Retina. 2012;32:499-505.

30. Holekamp NM, Shui YB, Beebe DC. Vitrectomy surgery in-creases oxygen exposure to the lens: a possible mechanism for nuclear cataract formation. Am J Ophthalmol. 2005;139:302-10.

31. Reibaldi M, Longo A, Avitabile T, et al. Transconjunctival Nonvitrectomizing vitreous surgery versus 25-gauge Vitrectomy in patients with Epiretinal membrane: A prospective randomized study. Retina. 2015;35(5):873-9.

\section{Publisher's Note}

Springer Nature remains neutral with regard to jurisdictional claims in published maps and institutional affiliations.

Ready to submit your research? Choose BMC and benefit from:

- fast, convenient online submission

- thorough peer review by experienced researchers in your field

- rapid publication on acceptance

- support for research data, including large and complex data types

- gold Open Access which fosters wider collaboration and increased citations

- maximum visibility for your research: over $100 \mathrm{M}$ website views per year

At BMC, research is always in progress.

Learn more biomedcentral.com/submissions 